\title{
O Processo de Internacionalização da Pós-Graduação Stricto Sensu Brasileira
}

\author{
Stella Maris Wolff da Silva ${ }^{1}$ \\ Ivan Rocha Neto ${ }^{2}$ \\ Maria Rosa Chitolina Schetinger ${ }^{3}$
}

\begin{abstract}
Resumo
Uma simples definição do termo "internacionalização" não esclarece o conteúdo e os limites em que se insere a internacionalização da Pós-Graduação stricto sensu, dada sua importância para a ciência e por ser um dos critérios de classificação na Avaliação Quadrienal realizada pela Coordenação de Aperfeiçoamento de Pessoal de Ensino Superior (Capes). Esta pesquisa procura demonstrar a evolução de certos programas de cooperação acadêmica internacional, executados pela instituição Capes, envolvendo o Brasil, a Alemanha, os Estados Unidos e a França, assim como os critérios de seleção desses países. A metodologia adotada é de natureza exploratória e explicativa e foi desenvolvida a partir do levantamento da literatura relativa à internacionalização da educação de Pós-Graduação stricto sensu brasileira, da revisão histórica da cooperação acadêmica internacional, desenvolvida pela Capes, e da apresentação de dados referentes às concessões de bolsas em virtude da cooperação desenvolvida entre 0 Brasil e os três países selecionados para esta pesquisa. A conclusão da pesquisa é que programas de cooperação acadêmica internacional estabelecem relações institucionais e pessoais com consequente repercussão na Pós-Graduação brasileira, com a qualificação dos recursos humanos, ampliação da produção científica, e por proporcionar visibilidade internacional.
\end{abstract}

Palavras-chave: Educação. Pós-Graduação stricto sensu. Programas de cooperação acadêmica internacional. Capes.

${ }^{1}$ Doutoranda em Educação em Ciências Química da Vida e Saúde pela Universidade Federal do Rio Grande do Sul (UFRGS), cuja tese encontra-se em desenvolvimento sob a orientação da professora doutora Maria Rosa Chitolina Schetinger e coorientação do professor doutor Ivan Rocha Neto.wolffsms@gmail.com

2 Doutor em Eletrônica pela University of Kent, na Inglaterra, e professor colaborador na Universidade Federal do Rio Grande do Sul.neto-ivan@ hotmail.com

3 Doutora em Ciências (Bioquímica) pela Universidade Federal do Paraná. Atualmente, é professora da Universidade Federal do Rio Grande do Sul. mariachitolina@gmail.com 


\title{
THE INTERNATIONALIZATION PROCESS OF THE BRAZILIAN STRICTO SENSU POST-GRADUATION
}

\begin{abstract}
A simple definition of the term "internationalization" does not clarify the content and limits of the internationalization of the stricto sensu postgraduate course, given its importance to science and because it is one of the classification criteria in the four-yearly evaluation carried out by the Coordination of Personnel Development of Higher Education (Capes). This research tries to demonstrate the evolution of certain international academic cooperation programs, implemented by the Capes institution, involving Brazil, Germany, the United States and France, as well as the selection criteria of these countries. The methodology adopted is of exploratory and explanatory nature and it was developed based on a survey of the literature on the internationalization of Brazilian postgraduate stricto sensu education, the historical review of international academic cooperation, developed by Capes, and the presentation of data relating to scholarship concessions by virtue of cooperation developed between Brazil and the three countries selected for this research. The conclusion of the research is that international academic cooperation programs establish institutional and personal relations with consequent repercussion in the Brazilian postgraduate, with the qualification of human resources, expansion of the scientific production and due to the international visibility.
\end{abstract}

Keywords: Education. Post-Graduation stricto sensu. International academic cooperation programs. Capes.

Recebido em: 10/7/2017

Aceito em: 16/3/2018 
A Cooperação Acadêmica Internacional pode ser entendida como "a expressão de um trabalho conjunto entre nações, visando contribuir e operar na busca de interesses para todos os participantes envolvidos" (SOUTO; REINERT, 2004, p. 1). Assim, por ser função da política de um país, tal cooperação torna-se a expressão do trabalho simultâneo dos países cooperantes por um objetivo comum, sendo que as Instituições de Ensino Superior (IESs) brasileiras, por meio desse trabalho conjunto, conseguem cumprir uma de suas atribuições que é a de incrementar a educação, a ciência, a tecnologia e a cultura.

Surgem duas questões que dizem respeito ao tema internacionalização no meio acadêmico: O que significa "tornar-se internacional" em termos acadêmicos? E qual é o sentido da internacionalização no âmbito do ensino de Pós-Graduação?

Entende-se que, na expressão "tornar-se internacional" ou "internacionalizar-se", o questionamento a respeito dos objetivos da internacionalização pode ser resumido a uma hipótese de natureza predominantemente institucional e a outra, de conteúdo acadêmico. Ao pensarmos no sentido institucional, a internacionalização poderia ser entendida simplesmente como um processo voltado para a mera aquisição de renome internacional em benefício próprio. E, no sentido acadêmico, ela poderia ser vista como ferramenta para o desenvolvimento da educação, da ciência e da tecnologia, por meio de colaboração e troca de experiência com docentes e pesquisadores estrangeiros, mais especificamente por meio de produção científica, estágios de pesquisa em universidades estrangeiras, participação em congressos internacionais, orientação de mestrandos e doutorandos e, no âmbito discente, por meio da concessão de bolsas de estudos no exterior no contexto de Mestrado, Doutorado, Pós-Doutorado e outros auxílios.

No contexto da internacionalização acadêmica, o fenômeno da globalização desafia as instituições educacionais, científicas e tecnológicas a se inserirem num ambiente de troca, transferência e utilização de novas competências e de geração de novos conhecimentos, fazendo com que as Instituições de Ensino Superior cumpram com outra atribuição legal, que é a criação e a divulgação de novos conhecimentos nos ambientes nacional e internacional. 
Destacam-se no Brasil duas importantes agências federais de fomento à pesquisa ou disseminação do conhecimento, a saber, a Coordenação de Aperfeiçoamento de Pessoal de Nível Superior (Capes) e o Conselho Nacional de Desenvolvimento Científico e Tecnológico (CNPq), que perceberam a necessidade de ampliarem suas ações para além do território nacional, firmando acordos de cooperação internacional com diversos países.

Dada sua atuação global, no que se refere à inserção acadêmica brasileira e à internacionalização da Pós-Graduação brasileira stricto sensu, a presente pesquisa contempla o papel desempenhado pela Capes que "cresceu e modificouse substancialmente ao longo do tempo, decorrente não só das transformações na configuração mundial, mas também devido ao crescimento e fortalecimento da pós-graduação brasileira" (ROSA, 2008, p. 61). Conforme histórico a ser descrito, a cooperação acadêmica internacional brasileira passou de um padrão de cooperação assimétrica, em que países desenvolvidos tentavam suprir o déficit de recursos humanos das Instituições de Ensino Superior (IES) para o modelo atual de cooperação, baseado na simetria de ações (ROSA, 2008, p. 61), o qual implica a existência de um trabalho conjunto de pesquisa entre os países cooperantes.

\section{A Participação da Capes na Expansão da Cooperação Acadêmica Internacional}

Ao se analisar o processo de internacionalização da educação superior, em particular de Pós-Graduação, verificou-se que esse processo passou por fases. Conforme descrito pelo Modelo de Canto (CANTO, 2005), no início a cooperação acadêmica internacional brasileira passou por um período de cooperação isolada, apesar de possuir, em sua origem, pretensões globais. As primeiras concessões foram feitas mediante bolsas de estudo no exterior até que, décadas depois, o país pudesse contar com uma importante massa crítica capaz de consolidar a Pós-Graduação stricto sensu, o que de fato aconteceu. A contextualização dessa evolução, proposta pelo referido modelo, encontra-se demonstrada no Quadro 1, a seguir: 
Quadro 1 - Modelo de Canto (2005)

- Estratégias adotadas pela academia brasileira

\begin{tabular}{|c|l|}
\hline Período & \multicolumn{1}{|c|}{ Características } \\
\hline 1920 & Treinamento da elite na Europa \\
\hline 1930 & $\begin{array}{l}\text { Fundação das primeiras universidades brasileiras, com o auxílio de } \\
\text { acadêmicos europeus }\end{array}$ \\
\hline 1950 & $\begin{array}{l}\text { Apoio estrangeiro para o desenvolvimento do sistema de ensino superior } \\
\text { e para a formação de estudantes no exterior }\end{array}$ \\
\hline 1960 & $\begin{array}{l}\text { Formação de estudantes em áreas prioritárias na Europa e nos EUA, e } \\
\text { intercâmbio de acadêmicos, majoritariamente financiados pelo governo } \\
\text { brasileiro }\end{array}$ \\
\hline $\begin{array}{l}\text { De 1970 à } \\
\text { atualidade }\end{array}$ & $\begin{array}{l}\text { Estabelecimento de programas bilaterais financiados pelo governo } \\
\text { brasileiro e seus parceiros; estabelecimento de programas multilaterais }\end{array}$ \\
\hline
\end{tabular}

Fonte: Canto (2005).

Desde sua criação, em 1951, a Coordenação de Aperfeiçoamento de Pessoal de Nível Superior (Capes) tem procurado cumprir seu objetivo de executar e consolidar os cursos de Mestrado e de Doutorado no território brasileiro e de auxiliar o Ministério da Educação (MEC) na elaboração de políticas públicas. Suas principais atuações envolvem: a avaliação da Pós-Graduação stricto sensu, ${ }^{4}$ divulgação da produção científica, formação de recursos humanos de alto nível no Brasil e no exterior e o incremento da cooperação científica internacional e, a partir de 2007, sua atuação se estendeu também à Educação Básica.

No recorte feito para esta pesquisa, foram selecionados países com certas particularidades, as quais serão detalhadas pela ordem cronológica da assinatura de seus acordos e pela temporalidade que a cooperação foi realizada com o Brasil, quais sejam:

- Os Estados Unidos são um dos países escolhidos por terem dado início à cooperação acadêmica brasileira, em 1956, por meio da Fundação Rockefeller, ${ }^{5}$ quando foram distribuídas 200 bolsas de estudo

4 A Avaliação do Sistema Nacional de Pós-Graduação, na forma como foi estabelecida a partir de 1998, é orientada pela Diretoria de Avaliação da Capes e realizada com a participação da comunidade acadêmico-científica, por meio de consultores ad hoc. A avaliação é atividade essencial para assegurar e manter a qualidade dos cursos de Mestrado e Doutorado no país.

5 Fundação Rockefeller foi criada em 1913, com a missão de promover, no exterior, o estímulo à saúde pública, ao ensino, à pesquisa e à filantropia. 
nas áreas de Medicina e Biologia e, conforme descrito no Quadro 1 , com o modelo das estratégias adotadas pela academia científica brasileira (ROSA, 2008), essa primeira fase foi a de cooperação individualizada. Em 1964 a Fundação Ford assinou acordo com a concessão de bolsas destinadas à formação de recursos humanos em ciências básicas, dando impulso ao crescimento da Pós-Graduação no Brasil.

- O segundo país escolhido, a França, deu início à segunda fase de nossa cooperação acadêmica internacional, agora com perfil institucionalizado, quando, por meio de seu Comitê Francês de Avaliação da Cooperação Universitária com o Brasil, assinou o acordo Capes/ Cofecub, visando a fomentar o intercâmbio entre IES, Institutos ou Centros de Pesquisa e Desenvolvimento públicos, brasileiros e franceses.

- A Alemanha, um dos três países da pesquisa, representado pelo Serviço Alemão de Intercâmbio Acadêmico (Daad), trouxe aos novos acordos à equivalência de ações e financiamentos dos países cooperantes, ou seja, parcerias em que os países cooperantes assumem os custos financeiros na mesma medida. Tal modelo de cooperação é o prevalente e é atualmente utilizado na cooperação acadêmica internacional, coordenada pela Capes.

Ao serem selecionados para a presente análise os referidos países, foram levados em conta aspectos de antiguidade e de atualidade. Quanto ao aspecto de antiguidade, destacamos a cooperação entre o Brasil e os EUA e entre o Brasil e a França, sendo eles os precursores da cooperação acadêmica internacional brasileira; já em relação ao aspecto de atualidade, destaca-se a cooperação iniciada pela Alemanha, no início do século 21, com a assinatura do acordo Capes/ Daad, que trouxe inovação à cooperação e deu início à simetria de ações e de financiamentos, configurando a atual cooperação acadêmica brasileira.

Ao detalharmos o início da cooperação acadêmica internacional brasileira, sob a responsabilidade da Capes, entende-se que a primeira fase iniciada com a criação do Programa Universitário, em que a cooperação internacional 
foi vista como o principal instrumento para o aperfeiçoamento de nossos recursos humanos, e, com a vinda de pesquisadores estrangeiros, foi possível a estruturação dos primeiros cursos stricto sensu. Esse período isolacionista e individualizado durou décadas, até que aqueles primeiros acordos internacionais fossem assinados pelas Fundações Rockefeller, em 1956, e Ford, em 1964 (CANTO, 1999, p. 126). E, com o fortalecimento da comunidade científica, o Sistema Nacional de Pós-Graduação (SNPG) ${ }^{6}$ já contava, em 1976, com 561 cursos de Mestrado e 200 de Doutorado. Fechando-se um ciclo, abriu-se outro, por sinal, de grandes proporções, com a assinatura do acordo Capes/Cofecub, em 1978, que deu início a uma colaboração internacional institucionalizada, em que grupos de pesquisadores franceses interagiram com grupos de pesquisadores brasileiros. Esse ciclo de cooperação era tido como parcial, por ter como característica um fluxo desigual, em que saíam mais estudantes brasileiros do que entravam estrangeiros. Esse ciclo perdurou por quase duas décadas.

A grande guinada de nossa cooperação aconteceu com a entrada do século 21 e é o que permanece nos dias atuais. Agora, a colaboração acadêmica internacional é simétrica, com um modelo igualitário de trocas, sem assistencialismo, em que há compartilhamento de ideias, pesquisas e do custeamento financeiro entre os países cooperantes.

Quando o tema internacionalização foi proposto às Instituições de Ensino Superior (IESs), na década de 90, a Capes deliberou que os programas de Pós-Graduação stricto sensu, em funcionamento no SNPG, deveriam se adequar aos padrões internacionais, para fins de avaliação das atividades de pesquisa e de Pós-Graduação desenvolvidas nas IESs. Tal adequação foi realizada de

6 O Sistema Nacional de Pós-Graduação (SNPG) é constituído por meio de etapas: a primeira é a avaliação das propostas de cursos novos, em que, para a admissão de novos programas e cursos ao SNPG, a Capes avalia a qualidade das propostas e se elas atendem ao padrão de qualidade requerido desse nível de formação e encaminha os resultados desse processo para, nos termos da legislação vigente, fundamentar a deliberação do CNE/MEC sobre o reconhecimento de tais cursos e sua incorporação ao SNPG. A Avaliação dos Programas de Pós-Graduação compreende a realização do acompanhamento anual e da avaliação trienal do desempenho de todos os programas de Pós-Graduação que integram o SNPG. Os resultados desse processo, expressos pela atribuição de uma nota na escala de 1 a 7, fundamentam a deliberação do CNE/MEC sobre quais cursos obterão a renovação de "reconhecimento", a vigorar no triênio subsequente, agora quadriênio. 
forma induzida, numa ação acertada entre governo e IESs, cuja finalidade era a criação de uma massa crítica capaz de impulsionar o desenvolvimento científico nacional. Conforme enfatizam Souto e Reinert (2004), a cooperação acadêmica internacional é entendida como "parte integrante da política de um país", sendo expressa pelo "trabalho conjunto entre nações, visando contribuir e operar na busca de objetivos de interesse para todos os participantes envolvidos".

O papel da Capes, na ampliação da cooperação acadêmica internacional e no fortalecimento da Pós-Graduação stricto sensu, é crescente e notório e se constata o aumento de suas atividades, com o incremento dos programas com caráter internacional mediante a aplicação de 7 (sete) ações:

\begin{abstract}
A) Programas de concessão de bolsas no exterior; B) Programas que fomentam a criação de colégios doutorais, objetivando a dupla diplomação para o Doutorado; C) Financiamento a projetos conjuntos de pesquisa entre brasileiros e estrangeiros; D) Desenvolvimento de parcerias universitárias binacionais; E) Programas que fomentam a atração de pesquisadores e docentes estrangeiros; F) Programas interinstitucionais de fomento à criação conjunta de cursos stricto sensu no país e no exterior; e G) Programas especiais de incentivo à formação científica e de formação de professores (ROSA, 2008, p. 88).
\end{abstract}

Assim, essa agência, objetivando a ampliação das atividades da Pós-Graduação brasileira em âmbito mundial e a excelência da nossa comunidade científica, estabeleceu parcerias com outros países, ampliando o leque já existente: Argentina, Bélgica, Canadá, Chile, China, Colômbia, Cuba, Espanha, Haiti, Holanda, Israel, Itália, Japão, México, Noruega, Portugal, Reino Unido, Suécia, Timor Leste e Uruguai.

No quadro 2, a seguir, são referenciados os países que fazem parte do escopo desta pesquisa e os respectivos programas de cooperação internacional em vigência. Ressalta-se que, na Capes, a execução desses projetos internacionais está sob a responsabilidade de sua Diretoria de Relações Internacionais (DRI).

Explicita-se, entre as ações da DRI/Capes, os acordos bilaterais que procuram fomentar os Projetos Conjuntos de Pesquisa (PCP) e que possuem como particularidade a seleção de grupos formados por pesquisadores ligados 
a cursos de Pós-Graduação de excelência, notas 5,6 ou 7 obtidas na última avaliação realizada pela Agência e, em contrapartida, por grupos estrangeiros selecionados pelas regras de suas agências de fomento à pesquisa. Aos projetos selecionados é dado financiamento de missões de trabalho (intercâmbio de professores), bolsas de estudo (intercâmbio de alunos) e custeio. O outro tipo de programa, o de Parcerias Universitárias Binacionais (PUB), possui natureza institucional e objetiva o estabelecimento da cooperação bilateral, por meio de projetos de parcerias universitárias com o objetivo de ampliar o intercâmbio de estudantes de Graduação, o fomento ao intercâmbio de alunos de Pós-Graduação e de professores, com o reconhecimento mútuo dos créditos devendo ser garantido. Outro tipo de apoio é o de concessão de bolsas individuais, que visa à complementação dos cursos de Pós-Graduação brasileiros no aperfeiçoamento de recursos humanos, com a consequente melhoria dos ambientes acadêmico e de pesquisa.

Quadro 2 - Programas de Cooperação Acadêmica Internacional coordenados pela Capes entre o Brasil e a Alemanha, os Estados Unidos e a França

\begin{tabular}{|l|l|l|}
\hline País & \multicolumn{1}{|c|}{ Programa } & \multicolumn{1}{|c|}{ Tipo de Programa } \\
\hline \multirow{5}{*}{$\begin{array}{l}\text { Estados } \\
\text { Unidos }\end{array}$} & $\begin{array}{l}\text { FULBRIGHT 1-Prof. Assistente } \\
\text { de Língua Portuguesa; 2-MFA; }\end{array}$ & Bolsa individual \\
& $\begin{array}{l}\text { 3-Estágio Doutoral; 4- Estágio Pós- } \\
\text { doutoral em Ciências Humanas, } \\
\text { Sociais, Letras e Artes; 5-Prof. } \\
\text { Visitante; 6- Programa Nexus e e }\end{array}$ & \\
& $\begin{array}{l}\text { 7-Programa Profissional à Prof. de } \\
\text { Língua Inglesa nos EUA (PDPI }\end{array}$ & \\
\cline { 2 - 3 } & $\mathrm{NIH}^{4}$ & Bolsa individual \\
\cline { 2 - 3 } & $\mathrm{NSF}^{5}$ & PCP \\
\cline { 2 - 3 } & Tamu $^{6}$ & PCP \\
\cline { 2 - 3 } & $\mathrm{CWRU}^{7}$ & PCP \\
\cline { 2 - 3 } & $\mathrm{Setec/Capes/Nova}^{8}$ & Bolsa individual \\
\hline
\end{tabular}




\begin{tabular}{|c|c|c|}
\hline \multirow{6}{*}{ França } & Brafitec $^{9}$ & Projeto Conj. Pesquisa (PCP). \\
\hline & Brafagri $^{10}$ & Parceria Univ. Binacional (PUB). \\
\hline & Cofecub $^{11}$ & PCP \\
\hline & Embrapa/Fundação Acrópoles & PCP \\
\hline & Math AmSud ${ }^{12}$ & PCP \\
\hline & Stic AmSud $^{13}$ & PCP \\
\hline \multirow{9}{*}{ Alemanha } & Capes $/ \mathrm{Daad}^{14} / \mathrm{CNPq}$ & Bolsa individual \\
\hline & \begin{tabular}{|l|l} 
Missões de Curta Duração a \\
doutorandos brasileiros
\end{tabular} & Bolsa individual \\
\hline & Probral $^{15}$ & PCP \\
\hline & $\mathrm{I}-\mathrm{NoPa}^{16}$ & PCP \\
\hline & Bragecrim $^{17}$ & PCP \\
\hline & Humboldt $^{18}$ & Bolsa individual \\
\hline & $\mathrm{NoPa}^{19}$ & PCP \\
\hline & Bragfost $^{20}$ & Apoio à realização de evento \\
\hline & GTA $^{21}$ & Bolsa individual \\
\hline
\end{tabular}

Fonte: Dados extraídos do site da Capes. Disponível em: <http://www.capes.gov.br/cooperacao-internacional>. Acesso em: 18 maio 2017.

Legendas:

(1) Fulbright - Comissão para o intercâmbio educacional entre os EUA e o Brasil

(2) Programa Nexus de Redes Regionais de Pesquisa Aplicada

(3) PDPI- Desenvolvimento Profissional de Professores de Língua Inglesa

(4) NIH - National Institutes of Health (Instituto Nacional da Saúde)

${ }^{(5)}$ NSF (Biodiversidade) National Science Foundation (Fundação Nacional da Ciência)

(6) Tamu - Texas A\&M Foundation

(7) CWRU - Case Western Reserve University - Programa de Mobilidade de Estudantes de Engenharia.

${ }^{(8)}$ Setec/Capes/Nova - Sec de Educação Científica e Tecnológica e Northern Virginia Community College

(9) Brafitec - Programa de Intercâmbio de Estudantes de Graduação em Engenharia Brasil/França

${ }^{(10)}$ Brafragri - Brasil/França Agricultura

${ }^{(11)}$ Cofecub - Cooperação Francesa com Universidades Brasileiras

(12) Math AmSud - Matemática - América do Sul

(13) Stic AmSud - Ciências e Tecnologias da Informação e da Comunicação - América do Sul

(14) Daad - Serviço Alemão de Intercâmbio Acadêmico

(15) Probral - Programa Brasil-Alemanha

(16) I-NoPa - Novas Parcerias Integradas de Inovação Tecnológica/Capes/Daad e GIZ (Gesellschaft für Internationale Zusammenarbeit)

(17) Bragecrim - Programa Brasil-Alemanha para Pesquisa Conjunta em Tecnologia de Manufatura

${ }^{(18)}$ Humboldt - Fundação Alexander von Humboldt (AvH)

(19) NoPa - Novas Parcerias temas definidos pelos Grupos Assessores Temáticos (Proteção e Uso Sustentável das Florestas Tropicais ou Energias Renováveis e Eficiência Energética)

(20) Bragfost - Simpósio Brasil-Alemanha em Fronteiras da Ciência e Tecnologia

(21) GTA - Programa de Assistente de Ensino de Língua Alemã 
Percebe-se que as ações da Agência visam ao apoio aos Programas de Pós-Graduação (PPGs) na busca da ampliação de suas opções de internacionalização institucional, critérios de aferição da Avaliação na busca de sua excelência de acordo com o que se encontra especificado no atual Plano Nacional de Pós-Graduação (PNPG), a saber, de que a demanda por internacionalização pode ser considerada o fator de mais alto impacto na conceituação de um programa de Pós-Graduação (BRASIL, 2010). Ainda em suas ações, a Agência ampliou as concessões individualizadas e institucionalizadas, e diversificou a natureza e a parceria dos novos acordos firmados. Verifica-se renovação e adequação de suas ações aos anseios da nossa comunidade científica, em constante crescimento.

Diante do exposto, infere-se que a educação brasileira de Pós-Graduação tem-se consolidado e obtido o reconhecimento neste país e fora dele e que sua participação na produção científica mundial está inserida na chamada globalização, processo que procura dar amplitude ao que se produz num país, a exemplo da educação, ciência, tecnologia, economia, cultura, que têm crescido, conforme demonstram dados de publicações científicas em colaboração internacional publicados no SCImago Journal \& Country Rank (SJR). As Figuras 1 e 2 apresentam dados referentes à participação brasileira na produção científica mundial; a primeira diz respeito à publicação de pesquisadores brasileiros com colaboração internacional e a segunda apresenta a boa posição do Brasil na produção científica internacional em comparação aos outros 238 países avaliados.

Figura 1 - Participação brasileira na produção científica mundial com colaboração internacional

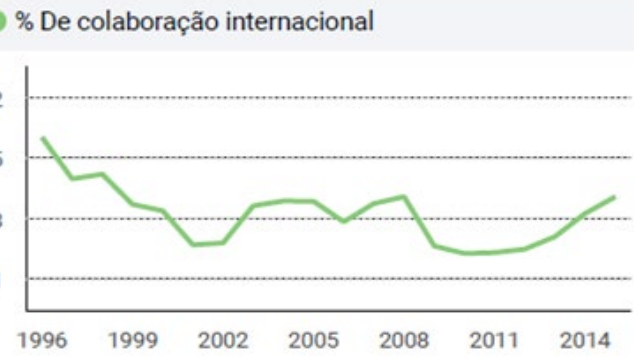

Fonte: Dados extraídos do SCImago Journal \& Country Rank (SJR), 2017. 
A Figura 1 indica a proporção dos documentos de um periódico assinados por pesquisadores de mais de um país. Nela pode ser observado que, após sucessivas quedas, houve aumento no número de publicações com colaboração internacional no período de 2011 a 2014, último biênio.

A Figura a seguir indica a posição do Brasil, em termos de produção científica, em relação aos 3 países envolvidos na pesquisa, Alemanha, Estados Unidos e França, entre outros.

Figura 2 - Ranking de 20 Países na Produção Científica Mundial no período de 1996-2016

$\begin{array}{lccccccc}\text { Rank } & \text { Country } & \text { Document } & \begin{array}{c}\text { Citable } \\ \text { doc. }\end{array} & \text { Citations } & \begin{array}{c}\text { Self- } \\ \text { citations }\end{array} & \begin{array}{c}\text { Citations per } \\ \text { document }\end{array} & \text { H index } \\ \mathbf{1} & \text { United States } & \mathbf{1 0 1 9 3 9 6 4} & \mathbf{9 1 6 5 2 7 1} & \mathbf{2 4 0 3 6 3 8 8 0} & \mathbf{1 1 0 5 1 7 0 5 8} & \mathbf{2 3 , 5 8} & \mathbf{1 9 6 5} \\ 2 & \text { China } & 4595249 & 4525851 & 32913858 & 18210007 & 7,16 & 655 \\ 3 & \text { United } & 2898927 & 2499445 & 60988844 & 13948928 & 21,04 & 1213 \\ & \text { Kingdom } & & & & & & \\ \mathbf{4} & \text { Germany } & \mathbf{2 5 7 0 2 0 6} & \mathbf{2 3 9 4 1 5 8} & \mathbf{4 9 0 2 3 2 0 7} & \mathbf{1 2 1 5 8 5 6 3} & \mathbf{1 9 , 0 7} & \mathbf{1 0 5 9} \\ 5 & \text { Japan } & 2367977 & 2277777 & 35480575 & 9503478 & 14,98 & 871 \\ \mathbf{6} & \text { France } & \mathbf{1 8 2 6 7 0 8} & \mathbf{1 7 1 2 3 1 2} & \mathbf{3 3 9 1 0 9 5 5} & \mathbf{7 2 9 2 4 7 8} & \mathbf{1 8 , 5 6} & \mathbf{9 6 6} \\ \mathbf{7} & \text { Canada } & 1468796 & 1338700 & 31052115 & 5578703 & 21,14 & 963 \\ 8 & \text { Italy } & 1449301 & 1335074 & 25366435 & 5850838 & 17,5 & 839 \\ 9 & \text { India } & 1302605 & 1223521 & 10839171 & 3694872 & 8,32 & 478 \\ 10 & \text { Spain } & 1148258 & 1060196 & 18244660 & 4201659 & 15,89 & 723 \\ 11 & \text { Australia } & 1111010 & 996160 & 20363776 & 4272355 & 18,33 & 795 \\ 12 & \text { South Korea } & 914572 & 887739 & 10741924 & 2220618 & 11,75 & 536 \\ 13 & \text { Russian } & 860847 & 842674 & 5947119 & 1831981 & 6,91 & 467 \\ & \text { Federation } & & & & & & \\ 14 & \text { Netherlands } & 816316 & 745545 & 20136037 & 3133734 & 24,67 & 835 \\ \mathbf{1 5} & \text { Brazil } & \mathbf{7 4 9 4 9 8} & \mathbf{7 1 5 1 7 0} & \mathbf{7 5 5 7 9 1 6} & \mathbf{2 5 0 1 8 3 8} & \mathbf{1 0 , 0 8} & \mathbf{4 6 1} \\ 16 & \text { Switzerland } & 595889 & 550777 & 15280692 & 1969916 & 25,64 & 818 \\ 17 & \text { Taiwan } & 575296 & 556749 & 6885565 & 1402557 & 11,97 & 406 \\ 18 & \text { Sweden } & 552343 & 514919 & 13028361 & 1926467 & 23,59 & 735 \\ 19 & \text { Poland } & 527034 & 509596 & 5048906 & 1282858 & 9,58 & 445 \\ 20 & \text { Turkey } & 485366 & 453565 & 4414662 & 1039323 & 9,1 & 339\end{array}$

Fonte: Dados extraídos do SCImago Journal \& Country Rank (SJR), 2017. 
Diante desse quadro de efetiva participação do Brasil, no que diz respeito à inserção de sua Pós-Graduação no cenário internacional, dados extraídos do portal GeoCapes referentes aos anos de 2013, 2014 e 2015 revelam o crescimento das concessões de bolsas pela Capes a brasileiros nos âmbitos do Doutorado, Doutorado-Sanduíche e Pós-Doutorado. É o que pode ser apreendido a partir da Figura 3, a seguir:

Figura 3 - Bolsistas brasileiros/Capes no exterior no período de 2013 a 2015

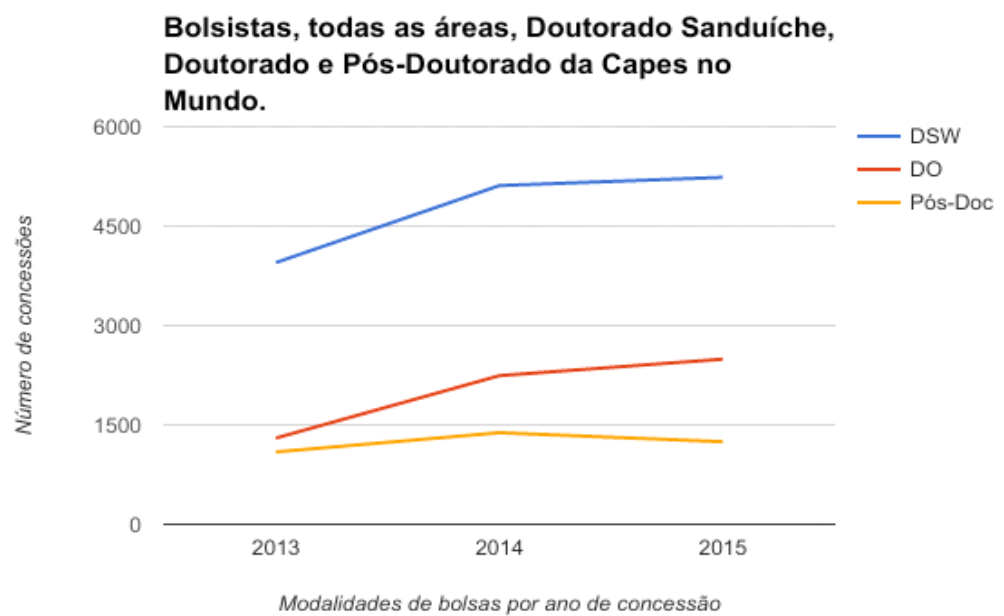

Fonte: Dados extraídos do portal GeoCapes

Foram extraídos do mesmo Portal GeoCapes dados publicados nesses três anos referentes às concessões de bolsas a discentes vinculados a Programas de Pós-Graduação em Ciências Biológicas II, conceitos 5, 6 e 7, que possuem cooperação internacional acadêmica com Alemanha, EUA ou França; constata-se um padrão de crescimento das concessões, com um aumento em 2014 e com uma leve queda no âmbito de Pós-Doutoramento em 2015. A pesquisa limitou-se aos níveis de bolsas estipulados pelos editais de chamada, quais sejam: Doutorado Pleno (DO), Doutorado-Sanduíche (SDW) e Pós-Doutorado (Pós-Doc). 
Figura 4 - Concessões de bolsas/2013 a discentes vinculados a Programas de Pós-Graduação em Ciências Biológicas II decorrentes da cooperação internacional acadêmica com Alemanha, EUA e França

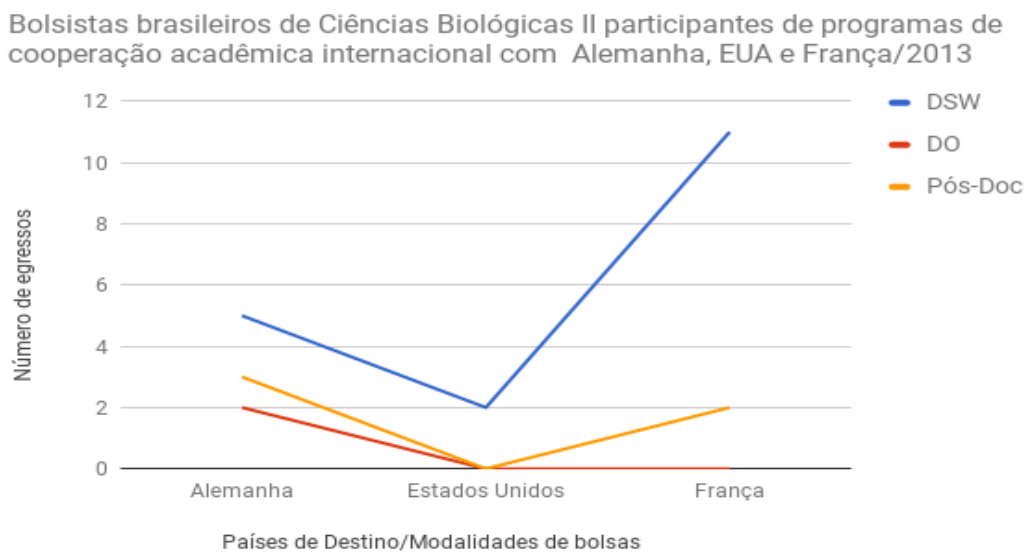

Fonte: Dados extraídos do portal GeoCapes.

Figura 5 - Concessões de bolsas 2014 a discentes vinculados a Programas de Pós-Graduação em Ciências Biológicas II decorrentes da cooperação internacional acadêmica com Alemanha, EUA e França

Bolsistas brasileiros de Ciências Biológicas II participantes de programa de cooperação acadêmica internacional com Alemanha, EUA e França em 2014

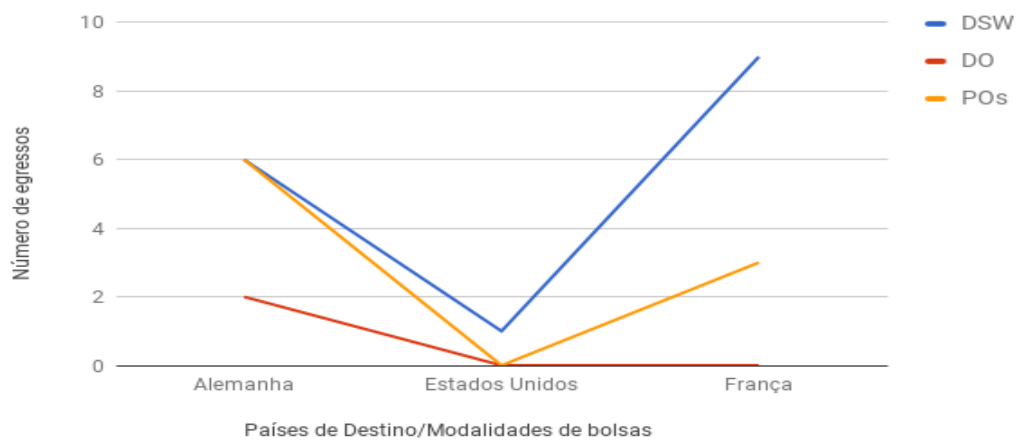

Fonte: Dados extraídos do portal GeoCapes. 
Figura 6 - Concessões de bolsas 2015 a discentes vinculados a Programas de Pós-Graduação em Ciências Biológicas II decorrentes à cooperação internacional acadêmica com Alemanha, EUA e França.

\section{Bolsistas brasileiros de Ciências Biológicas II participantes de programas de cooperação acadêmica internacional com Alemanha, EUA e França em 2015}

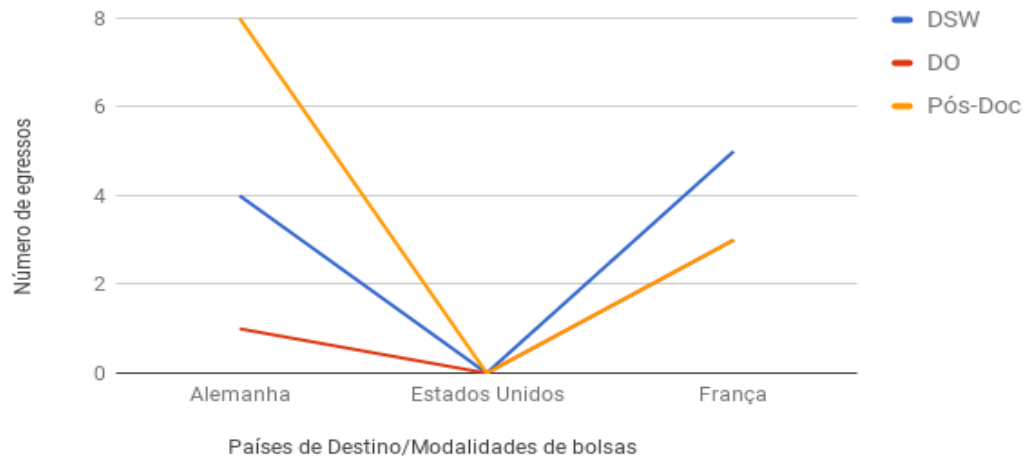

Fonte: Dados extraídos do portal GeoCapes.

Conforme demonstram as três figuras anteriores, há crescimento das concessões de bolsas, individuais ou vinculadas à cooperação acadêmica internacional, evidenciando que a Capes tem contribuído positivamente ao fortalecimento do SNPG com a formação qualificada de recursos humanos no exterior e consequente aumento da produção científica, dando mais visibilidade internacional à ciência brasileira.

\section{Fundamentos para a Cooperação Acadêmica Internacional}

Uma das metas do atual Plano Nacional de Pós-Graduação vem a ser a internacionalização da Pós-Graduação brasileira, um dos principais requisitos para que os programas de Pós-Graduação atinjam conceitos de excelência e, nesse sentido, Fiorin (2007) destaca que o grau de internacionalização da produção científica é considerado um dos critérios mais relevantes para se medir o mérito da produção. Conforme apresenta o Sistema Nacional de Pós-Graduação (SNPG), existem 4.381 programas de Pós-Graduação em funcionamento e 
cerca de $20 \%$ desse total possui conceito 5, 6 ou 7, demonstrando o caminho exitoso que a cooperação internacional brasileira tem traçado. Ressalte-se que notas superiores a 5 somente são atribuídas a programas com elevado padrão de excelência e que tenham cursos de Doutorado.

O artigo 43 da Lei de Diretrizes e Bases da Educação Nacional - LDB (BRASIL, 1996) declara que a internacionalização pode ser entendida como ferramenta necessária à consecução das finalidades estabelecidas para a educação superior. E a Constituição da República Federativa do Brasil (CRFB) (BRASIL, 1988), no inciso IX do artigo $4^{\circ}$ esclarece, sem explicitar, que a internacionalização guia-se tanto pelos princípios que regem as relações internacionais brasileiras quanto pelos princípios concernentes à educação, à ciência e à tecnologia, na busca da "cooperação entre os povos para o progresso da humanidade".

Dentro do conceito global da disseminação científica e do incentivo ao trabalho de pesquisa e investigação científica, visando ao desenvolvimento da ciência e da tecnologia e a criação e difusão da cultura, a Declaração Mundial sobre Educação Superior no Século 21: Visão e Ação - 1998, em documento organizado pela Organização das Nações Unidas para a Educação, a Ciência e a Cultura (Unesco), apresenta a Educação Superior definindo-a como [...] todo tipo de estudos, treinamento ou formação para pesquisa em nível pós-secundário, oferecido por universidades ou outros estabelecimentos educacionais aprovados como instituições de educação superior pelas autoridades competentes do Estado (ORGANIZAÇÃO..., 1998, p. 11).

O documento destaca a importância da Educação Superior para o século 21, quanto ao desenvolvimento sociocultural e econômico e que, para tanto, as questões voltadas para o seu acesso e expansão devem passar a ser intensificadas, completando que a sociedade do século atual é a do conhecimento.

Diante de tal alegação, atribuem-se à Educação Superior e à pesquisa a incumbência de realizar mudanças que visem ao desenvolvimento da sociedade e são, portanto, "componentes essenciais ao desenvolvimento cultural e socioeconômico de indivíduos, comunidade e nações” (ORGANIZAÇÃO..., 1998, p. 12). 
E assim, por entenderem que a universidade é, ou deveria ser, ambiente para congregarem-se pesquisa, conhecimento científico e tecnológico, a Educação Superior tem recebido enfoque especial nas políticas de governo e nas recomendações das Organizações Internacionais para os países em desenvolvimento.

Knight e Wit (1995) destacam ainda as seguintes fundamentações a respeito da importância da cooperação acadêmica internacional: melhoria da qualidade da educação e a qualificação de pessoal de nível superior.

1 - Quanto à melhoria da qualidade da educação:

- Reduzir as carências institucionais por meio do aproveitamento de uma série de oportunidades educativas e culturais; intercambiar professores e estudantes com instituições estrangeiras, em busca do aperfeiçoamento de sua formação nos níveis de graduação e pós-graduação e para atualização de conhecimentos;

- Melhorar a credibilidade nacional e internacional como um dos motivos para que as IES se internacionalizem (esse tem sido um dos critérios mais importantes adotados pela Capes no processo de avaliação da qualidade dos programas de pós-graduação) e

- Ensejar educação de alto nível, com formação de parcerias e em cooperação com instituições internacionalmente reconhecidas, observando-se a qualidade dos programas de pós-graduação, facilitando a mobilidade acadêmica e profissional.

2 - Quanto à formação e qualificação de pessoal de nível superior

- A formação, qualificação e experiência dos atores envolvidos, por estes conviverem com diferentes culturas e sociedades, bem como devido à experiência acadêmico-profissional adquirida, ao retornarem ao seu país de origem, espera-se que estejam prontos a transmitirem seus conhecimentos e consigam gerar novos empregos.

Circunstanciada por Knight (2005), a internacionalização da educação compreende um processo deliberado de introdução de dimensões internacionais, de caráter intercultural nos aspectos que envolvem atividades de ensino e pesquisa. Atualmente, a experiência adquirida fora do país apresenta-se como critério nos mercados de trabalho, profissional e acadêmico. 
Diante do que foi supramencionado, a cooperação acadêmica internacional executada pelos PPG stricto sensu no Brasil, por meio da Capes, qualifica recursos humanos de alto nível, contribui para o aperfeiçoamento e visibilidade da comunidade científica brasileira e amplia a produção científica, acarretando no crescimento do SNPG, tal qual se deu nas últimas décadas em âmbito global. Ainda, como consequência, devido ao crescimento e à excelência do SNPG, a demanda por bolsas plenas no exterior foi reduzida e a modalidade de bolsa sanduíche teve ampliação. Enfatiza-se que a eficácia da formação acadêmica no exterior, seja por meio de bolsa individual ou de missões de trabalho vinculadas aos acordos de cooperação internacional, amplia a formação e qualificação de recursos humanos com potencial para responder adequadamente às necessidades nacionais em curto espaço de tempo, e com menores custos, ou seja, de forma eficiente. Além disso, num curto prazo, reduz-se a necessidade de investimento em infraestrutura para o desenvolvimento de questões de pesquisa que ainda não foram consolidadas no Brasil ou nos países parceiros.

A conclusão dada por Stallivieri (2004) é a de que a cooperação acadêmica internacional interinstitucional fundamenta-se em condições que, se realmente efetivadas, resultam numa real cooperação e, consequentemente, em benefícios entre os parceiros. Assim, considera-se que os atores que protagonizam a cooperação possuem comprometimento, planejamento de seus objetivos, cumprimento das atividades dentro dos prazos de execução e avaliação das ações propostas e executadas.

A cooperação acadêmica internacional desenvolvida pela Capes sofreu alterações ao longo do tempo decorrentes do crescimento da Pós-Graduação no Brasil e da evolução científica do país (ROSA, 2008, p.86), adequando-se a uma comunidade científica brasileira madura e ao crescimento do SNPG, ampliando suas ações, criando novas modalidades de acordos, programas e auxílios, assumindo assim um papel indutor diante das demandas da comunidade acadêmica.

\section{Os Riscos da Globalização para a Educação Superior}

Podemos inferir que a globalização é um processo de integração das relações socioespaciais em constante transformação, em âmbito mundial, e que, com o transcorrer do tempo, faz com que ela cresça e se consolide. Nesse 
processo de globalização novos desafios são lançados, fazendo com que as IESs retomem sua finalidade original: a de produzir e disseminar o conhecimento universal (KNIGHT, 2005).

$\mathrm{Na}$ Conferência Mundial sobre Ensino Superior realizada pela Unesco em Paris (2008), um dos títulos, "As novas dinâmicas do ensino superior e pesquisas para a mudança e o desenvolvimento social", cujo item "Internacionalização, Regionalização e Globalização" descrevia que a cooperação internacional na Educação Superior deve ser baseada em solidariedade, respeito mútuo, promoção de valores humanísticos e no diálogo intercultural. Ainda no documento há o argumento de que as instituições de Educação Superior ao redor do mundo têm uma responsabilidade social de ajudar no desenvolvimento, por meio da crescente transferência de conhecimentos, cruzando fronteiras e trabalhando para encontrar soluções comuns; têm por objetivo a circulação do saber e oferece como sugestão para esse enfrentamento a formação de redes de universidades internacionais, as parcerias para pesquisa e o intercâmbio de estudantes e profissionais.

No cenário de globalização, a internacionalização da educação surge com uma nova perspectiva, ao entende-la como serviço e que, se ela for vista como mercadoria, deverá ser regulada pelo mercado, o que a levaria à perda de sua dimensão de direito humano, portanto universal e de responsabilidade do Estado. Dentro dessa visão, a Organização Mundial de Comércio (OMC), em 1995, no âmbito do Acordo Geral de Comércio de Serviços, apresentou orientação para a inclusão da educação como serviço e, assim, a OMC pontuou quatro campos em que se poderia proceder à internacionalização dos serviços: a) oferta transfronteiriça (o serviço cruza a fronteira, saindo para um país para ser consumido em outro. Nessa categoria estariam incluídos quaisquer tipos de cursos a distância e franquias de cursos); b) consumo no exterior (o consumidor cruza a fronteira. Representa a forma mais comum de comércio na educação, configura-se por meio da educação no exterior); c) presença comercial (o fornecedor cruza a fronteira estabelecendo-se e investindo em país estrangeiro. No campo da educação, isso acontece quando as universidades criam cursos ou instituições em países estrangeiros); e d) movimento temporário de pessoas 
físicas (o fornecedor cruza a fronteira na forma de um deslocamento de pessoas físicas). No campo da educação, configura-se como deslocamento de professores e outros profissionais da área de educação (CHAVES, 2016, p. 118-137).

Em seguida, os ministros da Educação da França, Alemanha, Itália e Reino Unido assinaram em Paris, em 1998, a "Declaração de Sorbonne", tendo como pressuposto o atendimento a uma sociedade globalizada e em constante mudança, mas que na verdade já projeta a construção de um Espaço Europeu de Ensino Superior protecionista. Após, foi assinada, em 1999, a "Declaração de Bolonha", por 29 ministros de Educação europeus signatários (45 Estados europeus subscreveram o documento, em 2010), com o objetivo de criarem o Espaço Europeu de Ensino Superior (EEES) competitivo e atrativo para estudantes europeus e de países de outras regiões do mundo, como estratégia da globalização focalizada nos movimentos de capitais, na informação, na tecnologia e na mobilidade de recursos humanos de alta qualificação, demarcando uma transferência internacional protegida de conhecimentos e tecnologias.

Segundo Antunes (2006), o processo da Declaração de Bolonha mostrou ser uma forma inovadora de fazer políticas educativas, em que os governos definem os compromissos em fóruns supranacionais, ratificados pelas instituições nacionais que, em caráter voluntário, dão adesão legítima à ausência de processos institucionalizados. A Declaração visa a aumentar a produtividade e a atratividade dos países europeus no campo educacional, associando a isso práticas de aprendizagem contínua e a superação de entraves burocráticos. Nessa perspectiva, pode-se inferir que tais processos, executados na Europa, possuem o intuito de expandir e qualificar a educação em nível superior, mostrando o caráter econômico de tais iniciativas.

Lamentavelmente e conforme descrições dessas Declarações, inferimos que, no chamado processo de globalização da educação, existe risco iminente de que a educação em todos os níveis seja transformada em mercadoria, tornando letra morta as indicações da Unesco, que dão à educação uma dimensão de justiça e equidade social. 


\section{Considerações Finais}

Este trabalho procurou discorrer sobre as etapas por que passou a cooperação acadêmica internacional brasileira com seu devido fortalecimento. Constatou-se que houve grande fluxo de pesquisadores até a criação das primeiras universidades, suscitando um ambiente propício com a fusão de pesquisadores franceses e brasileiros, estes últimos formados nos Estados Unidos, e pela institucionalidade trazida pelos alemães que concedeu inerência ao ensino, pesquisa e extensão.

A Capes, por ter sido incumbida de aperfeiçoar recursos humanos, definiu suas ações centradas na inserção internacional, por meio de convênios com as Fundações norte-americanas Rockefeller e Ford, com o governo francês, por meio da Capes/Cofecub, e com a Alemanha, por meio do seu Daad. Ainda sob a responsabilidade da Capes, a avaliação da Pós-Graduação brasileira stricto sensu estipulou critérios de qualidade, sendo a inserção internacional um deles. Tais critérios visam à excelência do ensino de Pós-Graduação, no contexto internacional, à consolidação da comunidade científica brasileira e ao desenvolvimento do ensino, da ciência e da tecnologia brasileiras.

É a partir da criação de novos acordos e modalidades, programas e auxílios, que a cooperação acadêmica internacional, coordenada pela Capes, tornou-se complexa e adequada às demandas da comunidade científica brasileira, sólida e ciente de sua importância. Essa cooperação demonstra sua importância nos dias atuais, atuando para o desenvolvimento e fortalecimento da ciência brasileira, e ela parece ter um futuro promissor, pois tais parcerias, além de sólidas, são baseadas na seriedade e confiança dos atores envolvidos, fazendo com que elas sejam interessantes para ambos os lados.

Conforme análise apresentada, constata-se que a Agência Capes tem adotado o princípio de que a necessária expansão e consolidação da qualidade da Pós-Graduação no Brasil pressupõe uma ininterrupta rede de cooperação entre as equipes acadêmicas brasileiras e estrangeiras, revelando-se esta premissa, portanto, necessária para a inserção internacional da nossa Pós-Graduação. Fato é que redes foram consolidadas, expandidas e renovadas e novos acordos foram 
firmados e outros, antigos, permanecem nos dias de hoje. Ações estratégicas culminaram na execução dos projetos de cooperação acadêmica internacional, elevando o número de doutores titulados, concedendo bolsas, auxílios e outros mecanismos (como projetos conjuntos), para a formação e capacitação de recursos humanos, promovendo a cooperação internacional no Sistema Nacional de Pós-Graduação, em áreas de interesse nacional, fomentando o desenvolvimento científico e tecnológico, com apoio à pesquisa, à inovação e, com isso, contribuindo para o estímulo e a valorização da educação, da ciência e da tecnologia e dando incremento à produção científica brasileira, conferindo-lhe mais visibilidade internacional.

\section{Referências}

ANTUNES, Fátima. Governação e espaço europeu de Educação: regulação da educação e visões para o projecto "Europa". Revista Crítica de Ciências Sociais, n. 75, p. 63-93, 2006. Disponível em: <https://rccs.revues.org/901>. Acesso em: $1^{\circ}$ jun. 2017.

BRASIL. Constituição da República Federativa do Brasil de 1988. Texto original publicado no Diário Oficial da República Federativa do Brasil, Brasília, DF, 5 out. 1988. Seção 1. Brasília, DF: Congresso Nacional, 1988. Disponível em: <http://www.planalto. gov.br/ccivil_03/constituicao/constituicao.htm>. Acesso em: 20 jun. 2016.

. Lei $n^{\circ}$ 9.394, de 20 de dezembro de 1996. Estabelece as diretrizes e bases da educação nacional. Texto original publicado no Diário Oficial da República Federativa do Brasil, Brasília, DF, 23 dez. 1996. Brasília, DF: Câmara dos Deputados, 1996. Disponível em: <http://www.planalto.gov.br/ccivil_03/leis/L9394.htm>. Acesso em: $1^{\circ}$ jun. 2017.

. Ministério da Educação. Coordenação de Aperfeiçoamento de Pessoal de Nível Superior. Plano Nacional de Pós-Graduação - PNPG 2011-2020. Tem como objetivo definir novas diretrizes, estratégias e metas para dar continuidade e avançar nas propostas para política de pós-graduação e pesquisa no Brasil. Brasília, DF: Capes, 2010. 2 v. Disponível em: <http://www.capes.gov.br/images/stories/download/Livros-PNPG-Volume-I-Mont.pdf>. Acesso em: 4 jul. 2017.

CANTO, Isabel. Brasil e a evolução da colaboração científica internacional. In: SARAIVA, José Flávio Sombra; CERVO, Amado Luiz (Org.). O crescimento das relações internacionais no Brasil. Brasília, DF: Instituto Brasileiro de Relações Internacionais (Ibri), 2005. p. 173-194. 
CANTO, Isabel; HANNAH, Janet. Revista Brasileira de Pós-Graduação. Brasília, v. 3, n. 6, p. 214-233, dez. 2006.

CANTO, M. I. L. A PartenerShip of Equals? A Study of Academic Collaboration Between Britain and Brazil. 1999. Tese (Doutorado) - Universtiy of Nottingham, 1999.

. GeoCapes. Brasília: Capes, 2017b. Disponível em: <http://www.capes.gov.br/ component/content/article/conteudo-estatico/6886-geocapes>. Acesso em: 22 maio 2017.

CHAVES, Vera Lúcia Jacob et al. Internacionalização da educação superior no Brasil: programas de indução à mobilidade estudantil. Revista Internacional de Educação Superior, v. 2, n. 1, p. 118-137, jan./abr. 2016. Disponível em: <http://ojs.fe.unicamp.br/ ged/riesup/article/view/7531/6387>. Acesso em: $1^{\circ}$ jun. 2017.

\section{COORDENAÇÃO DE APERFEIÇOAMENTO DE PESSOAL DE NÍVEL SUPERIOR} (CAPES). Cooperação internacional. Brasília: Capes, 2017a. Disponível em: <http:// www.capes.gov.br/cooperacao-internacional>. Acesso em: 18 maio 2017.

DECLARAÇÃO Mundial sobre Educação Superior no século XXI: visão e ação. Conferência Mundial sobre Educação Superior. Paris: Unesco, 1998. Disponível em: $<$ http://www.direitoshumanos.usp.br/index.php/Direito-a-Educação/declaracao-mundial-sobre-educacao-superior-no-seculo-xxi-visao-e-acao.html>. Acesso em: $1^{\text {o }}$ jun. 2017.

FIORIN, José Luiz. Internacionalização da produção científica: a publicação de trabalhos de ciências humanas e sociais em periódicos internacionais. Revista Brasileira de Pós -Graduação-RBPG. Brasília, v. 4, n. 8, p. 263-281, dez. 2007.

KNIGHT, Jane. Modèle d'internationalisation ou comment faire face aux réalités et enjeux nouveaux. In: ORGANISATION DE COOPÉRATION ET DE DÉVELOPPEMENT ÉCONOMIQUES. L'enseignement supérieur en Amérique Latine: la dimension internationale. Paris: Ocde, 2005. p. 11-45. Disponível em: <http://siteresources.worldbank.org/EDUCATION/Resources/278200-1099079877269/547664-1099079956815/ Higher_Ed_in_LAC_Intnal_Dimension_FR.pdf>. Acesso em: $1^{\circ}$ jun. 2017.

KNIGHT, Jane; WIT, Hans de. Strategies for internationalization of higher education: historical and conceptual perspectives. In: WIT, Hans de (Ed.). Strategies for Internationalization of Higher Education. Luna Negra: Amsterdam, 1995. p. 5-32.

ORGANIZAÇÃO DAS NAÇÕES UNIDAS PARA A EDUCAÇÃO, A CIÊNCIA E A CULTURA - Unesco. Declaração mundial sobre Educação Superior no século XXI: visão e ação. Marco Referencial de ação Prioritária para a mudança e o desenvolvimento da educação superior. Trad. Amós Nascimento. Piracicaba: Unimep, 1998. 
ROSA, Leonardo Osvaldo Barchini. Cooperação acadêmica internacional: um estudo da atuação da Capes. 2008. 126 f. Dissertação (Mestrado em Ciências Sociais) - Universidade de Brasília, Brasília, 2008. Disponível em: <http://repositorio.unb.br/handle/10482/6289>. Acesso em: $1^{\circ}$ jun. 2017.

SCIMAGO Journal \& Country Rank (SJR). Granada/Extremadura/Madri/Alcalá de Henares, Espanha: SJR, 2017. Disponível em: <http://www.scimagojr.com/countryrank. php>. Acesso em: 6 dez. 2017.

SILVA, Stella Maris Wolff da. Cooperação acadêmica internacional da Capes na perspectiva do programa Ciência sem Fronteiras. 2012. 113f. Dissertação (Mestrado em Educação em Ciências: Química da Vida e Saúde) - Universidade Federal do Rio Grande do Sul, Porto Alegre, Brasília, 2012. Disponível em: <http://hdl.handle.net/10183/69929>. Acesso em: $1^{\circ}$ jun.2017.

SOUTO, Álvaro José de; REINERT, José Nilson. Cooperação internacional interuniversitária: o caso da UFSC. In: COLÓQUIO INTERNACIONAL SOBRE GESTÃO UNIVERSITÁRIA NA AMÉRICA DO SUL, 4., 2004, Florianópolis. Anais eletrônicos... Florianópolis: UFSC, 2004. Disponível em: <https://repositorio.ufsc.br/handle/123456789/35579>. Acesso em: $1^{\text {o }}$ jun. 2017.

STALLIVIERI, Luciane. Estratégias de internacionalização das universidades brasileiras. Petrópolis: Editora da Universidade de Caxias do Sul, 2004.

VELHO, Léa. Formação de doutores no país e no exterior: estratégias alternativas ou complementares? Revista Dados - Revista de Ciências Sociais, Rio de Janeiro, v. 44, n. 3, p. 607-631, jul. 2001. 